\title{
Outcomes of patients with HIV and COVID-19 co-infection: a systematic review and meta-analysis
}

Celestin Danwang ${ }^{1 *} \mathbb{D}$, Jean Jacques Noubiap ${ }^{2}$, Annie Robert ${ }^{1}$ and Jean Cyr Yombi $^{3}$

\begin{abstract}
Background: Data on the association of human immunodeficiency virus (HIV) infection with adverse outcomes in patients with COVID-19 are conflicting. This systematic review and meta-analysis aimed to summarize the available information on the risk of hospitalization, severe disease, and death attributable to HIV in patients with COVID-19.

Methods: PubMed, EMBASE, Web of Science, and SCOPUS were searched through October 25, 2021, to identify relevant studies, without language restriction. A random-effects model was used to pool estimates.

Results: We included 44 studies reporting information from 38,971,065 patients with COVID-19. The pooled prevalence of HIV among COVID-19 patients was $26.9 \%$ (95\% Cl 22.7-31.3) and was significantly higher in studies conducted in Africa compared to those conducted elsewhere (118.5\%o [95\% Cl 84.8-156.9, 11 studies] vs 10.9\% [95\% Cl 8.8-13.2, 27 studies]). In pooled analyses of unadjusted odds ratio, HIV-positive individuals were more likely to be admitted to hospital (OR: 1.49; 95\% Cl 1.01-2.21, 6 studies) compared to HIV-negative individuals. In the adjusted (for age and sex) analyses, HIV was associated with an increased risk of death (hazard ratio: 1.76, 95\% Cl 1.31-2.35, 2 studies). However, HIV was not associated with the severity of the disease (OR: 1.28; 95\% Cl 0.77-2.13, 13 studies), or death (OR: $0.81 ; 95 \% \mathrm{Cl} 0.47 ; 1.41,23$ studies) in patients with COVID-19 in the meta-analysis of unadjusted odds ratio.
\end{abstract}

Conclusion: Our findings suggest that patients with HIV have an increased risk of hospital admission for COVID-19. HIV seems to be independently associated with increased risk of mortality in COVID-19 patient in adjusted analysis. However, this evidence was derived from only two studies.

Keywords: Outcomes, HIV, Systematic review, Meta-analysis

\section{Introduction}

The coronavirus 2019 (COVID-19) pandemic is imposing to the world a huge health, societal and economic burden [1-3]. Despite all the efforts that have been made to reduce the spread of the virus and limit its lethality, the death rate from COVID-19 remains high. Indeed, as of 3 November 2021, approximately 246,951,274

\footnotetext{
*Correspondence: danram07@yahoo.fr

${ }^{1}$ Epidemiology and Biostatistics Unit, Institut de Recherche

Expérimentale et Clinique, Université Catholique de Louvain, Brussels, Belgium

Full list of author information is available at the end of the article
}

cases of COVID-19 have been diagnosed worldwide and 5,004,855 associated deaths have been recorded [4]. Results from vaccination campaigns are promising, with a marked reduction in new infections regardless of the variant in vaccinated individuals compared to unvaccinated or partially vaccinated people [5-8].

Although all ages and profiles are likely to be affected by COVID-19, studies suggest that patients with co-morbidities are particularly at risk of adverse outcomes compared to those without [9-11]. For instance, patients with hypertension, obesity and diabetes are more likely to die, be admitted to intensive care units and have severe forms of the infection [9-11]. For some other diseases such original author(s) and the source, provide a link to the Creative Commons licence, and indicate if changes were made. The images or other third party material in this article are included in the article's Creative Commons licence, unless indicated otherwise in a credit line to the material. If material is not included in the article's Creative Commons licence and your intended use is not permitted by statutory regulation or exceeds the permitted use, you will need to obtain permission directly from the copyright holder. To view a copy of this licence, visit http://creativecommons.org/licenses/by/4.0/. The Creative Commons Public Domain Dedication waiver (http://creativeco mmons.org/publicdomain/zero/1.0/) applies to the data made available in this article, unless otherwise stated in a credit line to the data. 
HIV, the information on their association with adverse outcomes in patients with COVID-19 are conflicting [12-17]. However, some regions of the world like subSaharan Africa are at risk of having a burden of COVID19 drive by the proportion of HIV patients. Sub-Saharan Africa for example bored the highest burden of HIV and patients not receiving antiretroviral therapy (ART) [1821]. Among the 38 millions of patients living with HIV globally, 26 million are in this part of the continent, with a relatively high proportion not receiving ART compare to other region of the world $[18,19]$.

HIV causes immunodepression by depleting CD4 cells, thus reducing the capacity of the organism to defend against bacterial, fungal, parasitic, and viral infections such as COVID-19 [20, 22]. This vulnerability to infection is greater when the immunodepression is severe and the patient is not on ART making the patient at risk of opportunistic infections [23, 24]. The presence of 38 million people worldwide with HIV during this period of COVID-19, could therefore be challenging for health systems worldwide as more aggressive preventive and therapeutic measures might be needed for this population. It is therefore necessary for programmatic purposes, optimal allocation of public health interventions and prioritisation of care in a context of scarce resources due to the pandemic [25], to know whether, given the state of the art, people living with HIV are proportionally more affected than people without the disease, and whether they are at greater risk of pejorative outcome when affected by COVID-19.

Hence, this study aimed to summarize the available information on the risk of hospitalization, severe disease, and death attributable to HIV in patients with COVID-19 and to determine the proportion of patients co-infected with HIV among patients with COVID-19.

\section{Methods}

This review is reported in accordance with the PRISMA guidelines and is registered with PROSPERO CRD42021255993.

\section{Search strategy and eligibility criteria}

PubMed, EMBASE, Web Sciences, and SCOPUS were searched from 1 December 2019 to 25 October 2021 without language restriction for studies reporting the outcome of COVID-19 according to HIV status. Only studies involving patients with confirmed COVID-19 infection (polymerase chain reaction or rapid diagnostic test) were included. HIV positivity/negativity was defined as per reported by each study. Both study reporting on patients with a known HIV status prior to the COVID-19 pandemic, and those in which the diagnostic of HIV was made in patients with COVID-19 during hospitalisation were considered. Severe COVID-19 was defined as the presence of blood oxygen saturation $\leq 93 \%$; multiple organ dysfunction; respiratory failure; septic shock; dyspnoea; respiratory rate greater than $30 / \mathrm{min}, \mathrm{PaO} 2 / \mathrm{FiO} 2$ ratio $<300$, and/or lung infiltrates $>50 \%$ of the lung field within 24-48 h [26]. For duplicates or studies published in more than one report, or conducted on the same database, the one reporting the largest sample size was considered.

The detailed search strategy is presented in the Appendix (Additional file 1: Tables S1-S3). We included all studies with at least 20 participants in each group (with and without HIV) and reporting sufficient information to determine the number of hospital admissions, severe cases, or deaths in each group.

After removing duplicates, two investigators (CD, JJN) assessed the eligibility of the retrieved articles, first based on the title and abstract, then on full text. Disagreements between the two investigators were resolved by discussion and consensus.

\section{Data extraction and quality assessment}

In each study, we extracted the name of the first author, the year of publication, the country, the characteristics of the study population (proportion of men, age distribution), the total number of patients with and without HIV in the study, the number of patients with each outcome between those with and without HIV. For all studies reporting prevalence data, the Joanna Briggs Institute (JBI) critical appraisal tool for prevalence studies was used to assess the risk of bias [27], with the following ranges $0-3,4-6$ and 7-9 indicating high, moderate and low risk of bias, respectively. For the remaining studies, the JBI tool corresponding to the study design was used [28].

\section{Statistical analysis}

To obtain the overall proportion of HIV patients among COVID-19 patients, a DerSimonian-Laird randomeffects model for meta-analysis within the "meta" package of $\mathrm{R}$ was performed. Then, to estimate the overall risk of hospital admission, severe COVID-19, and the risk of death among HIV and COVID-19 co-infected patients, a random-effects model was run. A subgroup analysis was performed according to country location (USA vs. NonUSA, and Africa vs. Non-Africa).

In addition, adjusted odds ratios (OR) or hazard ratio (HR) when available (with their standard error) were pooled to obtain an adjusted estimate for each outcome where there were at least two studies. We have assessed the association between mortality and death with the two ways of measuring methods of associations, the odds ratio and the hazard ratio. Cochran and $\mathrm{I}^{2}$ statistics were 
used to assess and estimate the degree of heterogeneity in the meta-analysis $[29,30] . \mathrm{I}^{2}$ ranging from 0 to $40 \%$, $40-75 \%, 75-100 \%$ was considered as indicative of low, moderate, and substantial heterogeneity respectively. Visual inspection of the funnel plot and Egger's test were used to assess publication bias. A sensitivity analysis was performed to detect influential studies. A p-value of $\leq 0.05$ was considered statistically significant. All analyses were performed with R software, version 4.0.2.

\section{Results}

\section{Study selection and characteristics}

We found 8537 studies from literature searches, and finally included 44 studies reporting information from 38,971,065 patients with COVID-19 in the meta-analysis (Additional file 1: Fig. S1). Thirteen (41.9\%) studies were conducted in the USA. Twenty-eight studies were crosssectional studies, eight were cross-sectional analyses of a cohort study, three were case series and five were case controls. Twenty-eight of the 44 studies were multicentre. All studies included in the systematic review and meta-analysis were in English. The sex ratio, and age distribution of patients according to HIV status was greatly variable according to study as summarized in Table 1.

\section{Prevalence of HIV among patients with COVID-19}

Thirty-eight studies were included in the meta-analysis of prevalence information. The pooled prevalence of HIV among COVID-19 patients was $26.9 \%$ (95\% confidence interval [CI] 22.7-31.3) (Fig. 1) and was significantly higher in studies conducted in Africa compared to those conducted elsewhere (118.5\% [95\% CI 84.8-156.9, 11 studies] vs $10.9 \%$ [ $95 \%$ CI $8.8-13.2$, 27 studies]). The pooled prevalence of HIV among COVID-19 patients was $12.9 \%$ ( $95 \%$ CI $7.7-19.5,13$ studies) in the USA and was significantly lower compare with the figure outside the USA (49.2\%; 95\% CI 24.0-82.2, 25 studies) (P value: $0.002)$. The pooled prevalence of HIV among studies conducted on hospital records was $24.6 \%$ (95\% CI 20.4-29.1, 33 studies), while the figure for population-based studies was $56.8 \%$ (95\% CI 11.9-129.7, 5 studies) (Additional file 1: Figs. S1-S4).

\section{Risk of in-hospital admission associated with HIV infection} Based on the meta-analysis of six studies, HIV-positive COVID-19 participants were more likely to be admitted to hospital than HIV-negative patients (OR: 1.49 ; 95\% CI 1.01-2.21) (Fig. 2).

\section{Risk of severe COVID-19 associated with HIV infection} A meta-analysis of 13 studies including 13,016 HIVinfected individuals with COVID-19, and 1,744,014 HIV-uninfected individuals with COVID-19, shows that
HIV does not increase the likelihood of having severe COVID-19 (OR: 1.28; 95\% CI 0.77-2.13) (Fig. 3), even after stratification according to study's country of recruitment (Additional file 1: Figs. S5, S6).

\section{Risk of death from COVID-19 associated with HIV infection} Twenty-three studies were included in the unadjusted risk ratio meta-analysis and two (one from South Africa, and one multicentric) in the adjusted HR meta-analysis.

In unadjusted pooled analyses, there was no association between death from COVID-19 and HIV (OR: 0.81; 95\% CI $0.47 ; 1.41,23$ studies). However, in analyses adjusted for age and sex, HIV was associated with an increased risk of death (hazard ratio 1.76, 95\% CI 1.31-2.35; 2 studies) (Fig. 4).

There was no significant difference in the risk of death of patients co-infected with HIV and COVID-19, compare with those without HIV even when the analysis was stratified by country (Additional file 1: Figs. S7, S8).

\section{Publication bias and sensitivity analysis}

The funnel plot of the studies included in the prevalence meta-analysis shows some asymmetry which was confirmed by Egger's test ( $\mathrm{p}$-value $=0.01$ ) (Additional file 1: Fig. S9), suggesting the presence of publication bias. However, neither the funnel plot nor the Egger test indicated publication bias for studies included in the meta-analysis conducted to assess the risk of in-hospital admission, severe disease, or death (Additional file 1: Figs. S10-S12).

In the leave-one-out analysis, none of the studies included when omitted change the overall effect-size in all analyses except in the meta-analysis pertaining to mortality risk (Additional file 1: Figs. S13-S16). In the latter, the omission of the Jassap et al. study strongly influences the overall OR, without changing the direction of the association between HIV and COVID-19 mortality, which remains non-significant (Additional file 1: Fig. S16).

\section{Discussion}

The results of the current study suggest that co-infection with HIV is associated with an increased risk of hospital admission in people with COVID-19. Furthermore, based on the analysis of a limit number of studies, the meta-analysis of adjusted (for age and sex) hazard ratio showed that HIV increases the risk of death in patients with COVID-19. However, HIV was not associated with an increased risk of death or of developing severe disease in the unadjusted analysis. The influence of age and sex on the outcome of patients with COVID-19 is well known and has been previously published [31, 32]. The lack of evidence of higher risk of death in HIV patients 


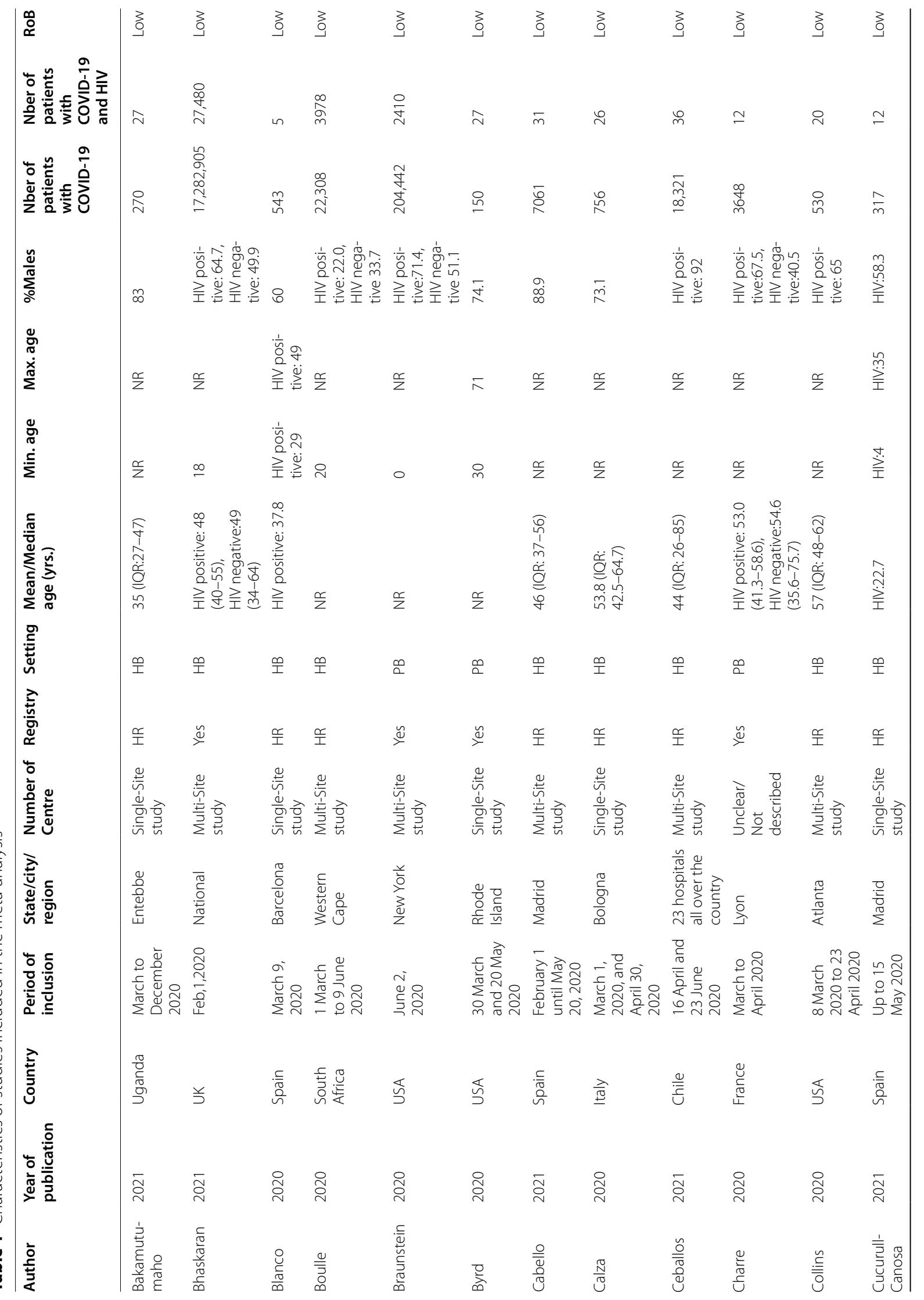




\begin{tabular}{|c|c|c|c|c|c|c|c|c|c|c|}
\hline$\stackrel{\infty}{\stackrel{0}{*}}$ & ב् & ב् & 吕 & ב⿱ & ב् & 3̧ & ב⿱ & ב⿱ & ב3 & 3 \\
\hline 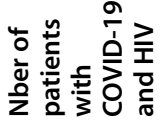 & $\bar{\sim}$ & 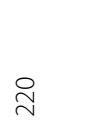 & $\nabla$ & $\underset{\beth}{\simeq}$ & $\stackrel{\infty}{\sim}$ & 字 & $\begin{array}{l}\stackrel{m}{\alpha} \\
\stackrel{m}{n}\end{array}$ & $\stackrel{\infty}{0}$ & $\underline{\sigma}$ & $\stackrel{\bullet}{ }$ \\
\hline 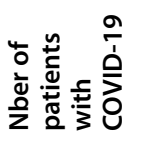 & $\stackrel{\gtrless}{\simeq}$ & $\stackrel{\stackrel{\infty}{N}}{\stackrel{N}{N}}$ & 品 & 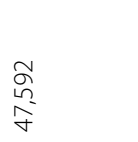 & 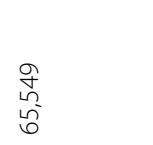 & $\begin{array}{l}\frac{0}{0} \\
\frac{0}{n}\end{array}$ & 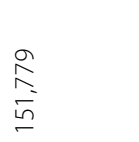 & $\stackrel{g}{\sim}$ & 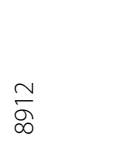 & 尺 \\
\hline$\frac{\tilde{y}}{\sum_{0}^{\frac{0}{0}}}$ & 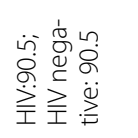 & 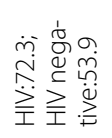 & ఫ্ं & 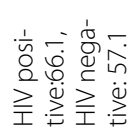 & 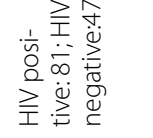 & 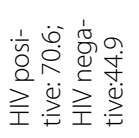 & 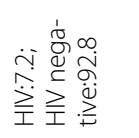 & 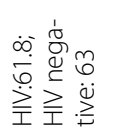 & 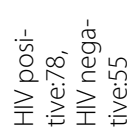 & g \\
\hline $\begin{array}{l} \\
\ddot{g} \\
\check{\pi} \\
\check{\pi} \\
\Sigma\end{array}$ & 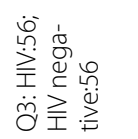 & $\stackrel{\Upsilon}{z}$ & $\stackrel{\frac{a}{z}}{2}$ & $\stackrel{\Upsilon}{z}$ & $\frac{⿱}{z}$ & $\frac{\mathscr{c}}{z}$ & $\frac{\mathscr{c}}{z}$ & 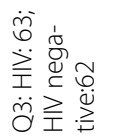 & $\stackrel{\frac{9}{z}}{2}$ & $\underset{\tilde{\tilde{O}}}{\stackrel{N}{O}}$ \\
\hline 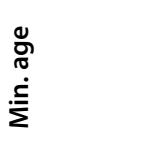 & 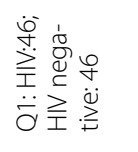 & $\frac{\propto}{z}$ & $\frac{\Re}{z}$ & $\stackrel{\Re}{z}$ & $\stackrel{\propto}{z}$ & $\stackrel{\circ}{-}$ & $\stackrel{\Upsilon}{z}$ & 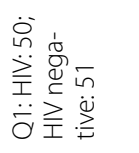 & $\frac{\Re}{z}$ & $\stackrel{\stackrel{m}{\bar{\sigma}}}{\stackrel{m}{0}}$ \\
\hline 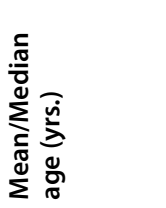 & 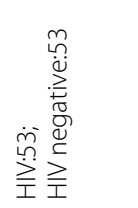 & 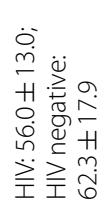 & $\stackrel{\Upsilon}{z}$ & 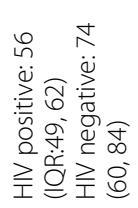 & 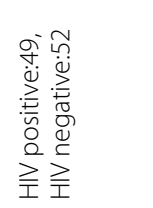 & 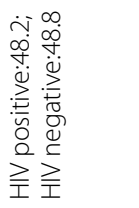 & $\frac{\mathscr{c}}{z}$ & 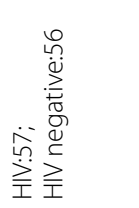 & $\frac{\mathscr{c}}{z}$ & $\stackrel{\infty}{\sim}$ \\
\hline 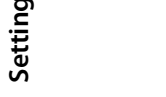 & 吕 & $\dddot{\Upsilon}$ & $\stackrel{\oplus}{\simeq}$ & $\stackrel{\oplus}{\Upsilon}$ & $\stackrel{\oplus}{I}$ & $\dddot{\Upsilon}$ & 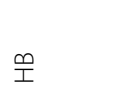 & $\stackrel{\oplus}{I}$ & $\stackrel{\oplus}{I}$ & $\stackrel{\oplus}{\underline{I}}$ \\
\hline 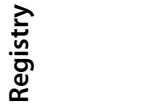 & $\stackrel{\dddot{I}}{\simeq}$ & 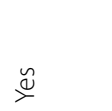 & $\stackrel{\dddot{I}}{\text { 促 }}$ & $\stackrel{\breve{̋}}{\simeq}$ & $\stackrel{\dddot{I}}{9}$ & $\stackrel{\check{\Perp}}{\varnothing}$ & 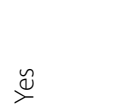 & $\stackrel{\dddot{I}}{\text { 促 }}$ & $\stackrel{\dddot{I}}{\simeq}$ & $\stackrel{\dddot{I}}{\underline{I}}$ \\
\hline 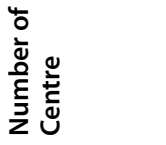 & 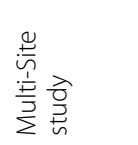 & 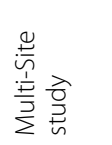 & 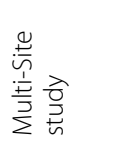 & 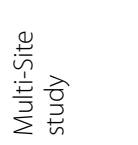 & 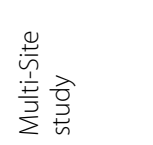 & 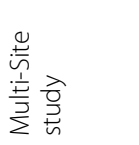 & 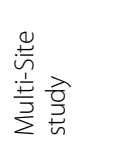 & 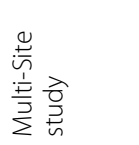 & 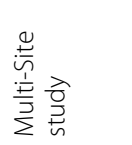 & 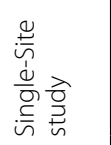 \\
\hline 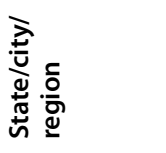 & 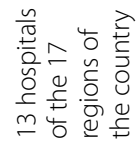 & 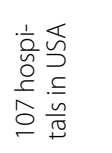 & 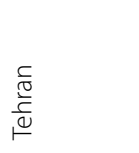 & 竞兽 & 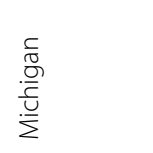 & 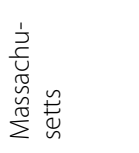 & 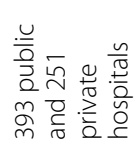 & 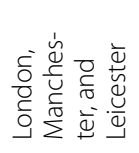 & $\begin{array}{l}\frac{\pi}{0} \\
\mathbb{\pi}\end{array}$ & $\stackrel{\sqrt[3]{0}}{\stackrel{\sqrt[0]{0}}{3}}$ \\
\hline 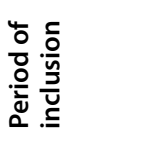 & 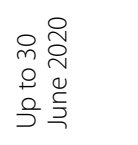 & 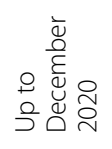 & 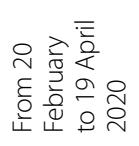 & 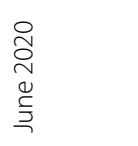 & 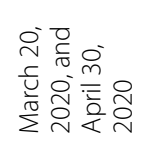 & $r$ & 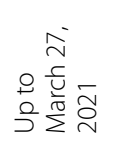 & 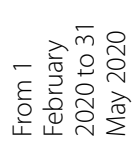 & 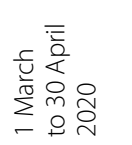 & 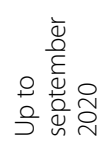 \\
\hline & 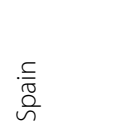 & 芆 & $\underset{\mathbb{\varpi}}{\stackrel{\complement}{=}}$ & 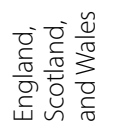 & 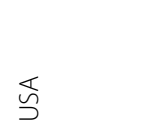 & 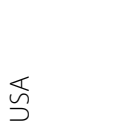 & 吾总 & 兰 & $\begin{array}{l}\stackrel{\nwarrow}{\bar{\sigma}} \\
\stackrel{0}{\sim}\end{array}$ & $\begin{array}{l}\frac{.0}{0} \\
\frac{E}{\tilde{N}} \\
\text { N }\end{array}$ \\
\hline 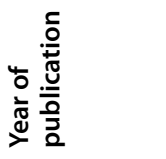 & 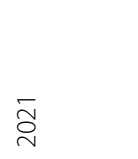 & $\overline{\tilde{\sigma}}$ & ্ָণ & ̊̊ & ̊̊̊ి & ర్ & $\overline{\widetilde{\sim}}$ & $\overline{\widetilde{\sim}}$ & 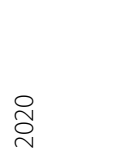 & $\overline{\widetilde{N}}$ \\
\hline 高 & $\stackrel{\stackrel{N}{O N}}{\square}$ & 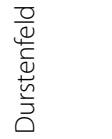 & 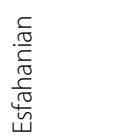 & $\begin{array}{l}\text { 恶 } \\
\text { Uू }\end{array}$ & $\begin{array}{l}\overline{\overline{0}} \\
\frac{0}{\overline{9}} \\
\overline{3} \\
0\end{array}$ & I & . & $\underset{\Xi}{\Xi}$ & 离兑 & 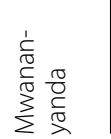 \\
\hline
\end{tabular}




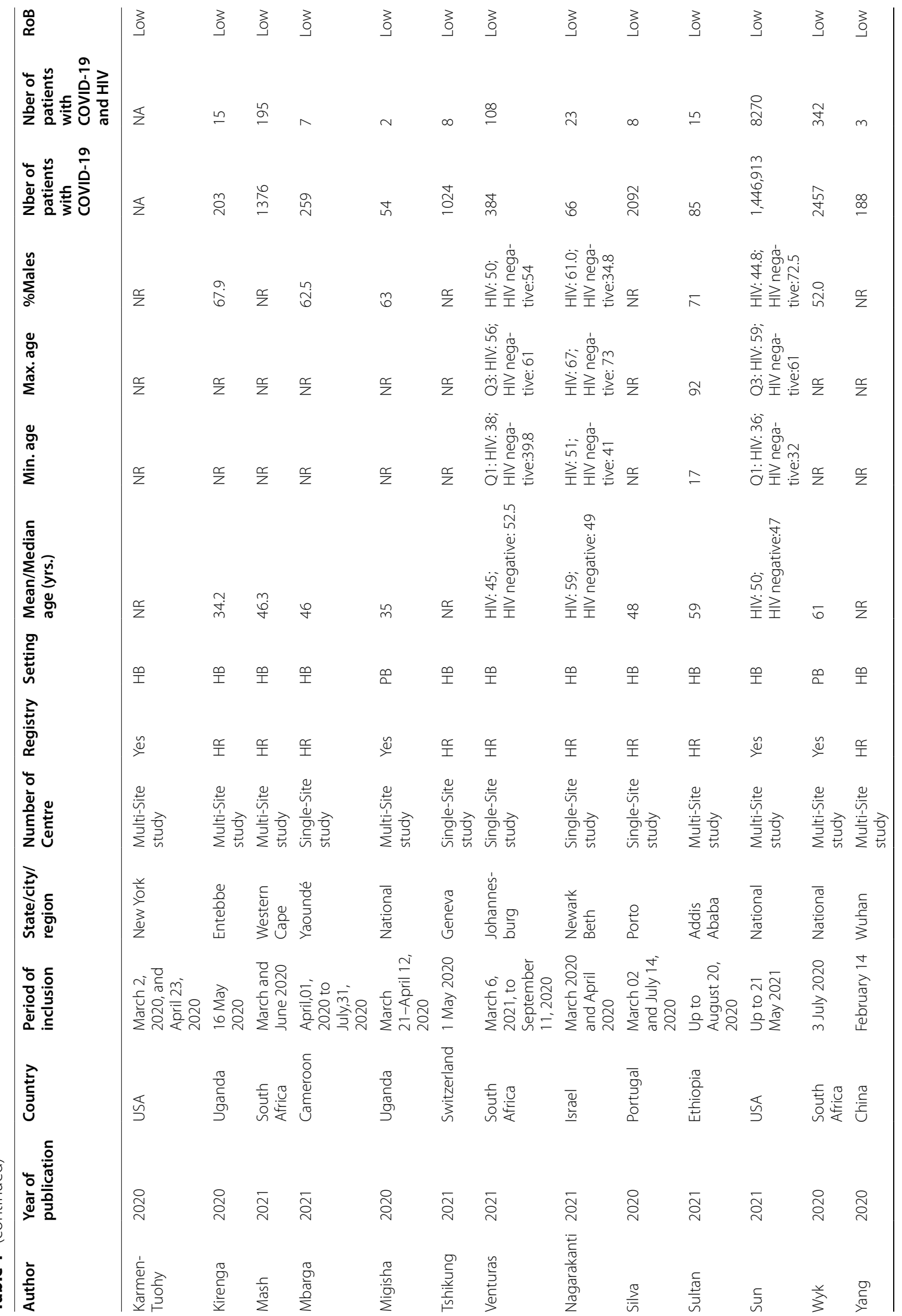




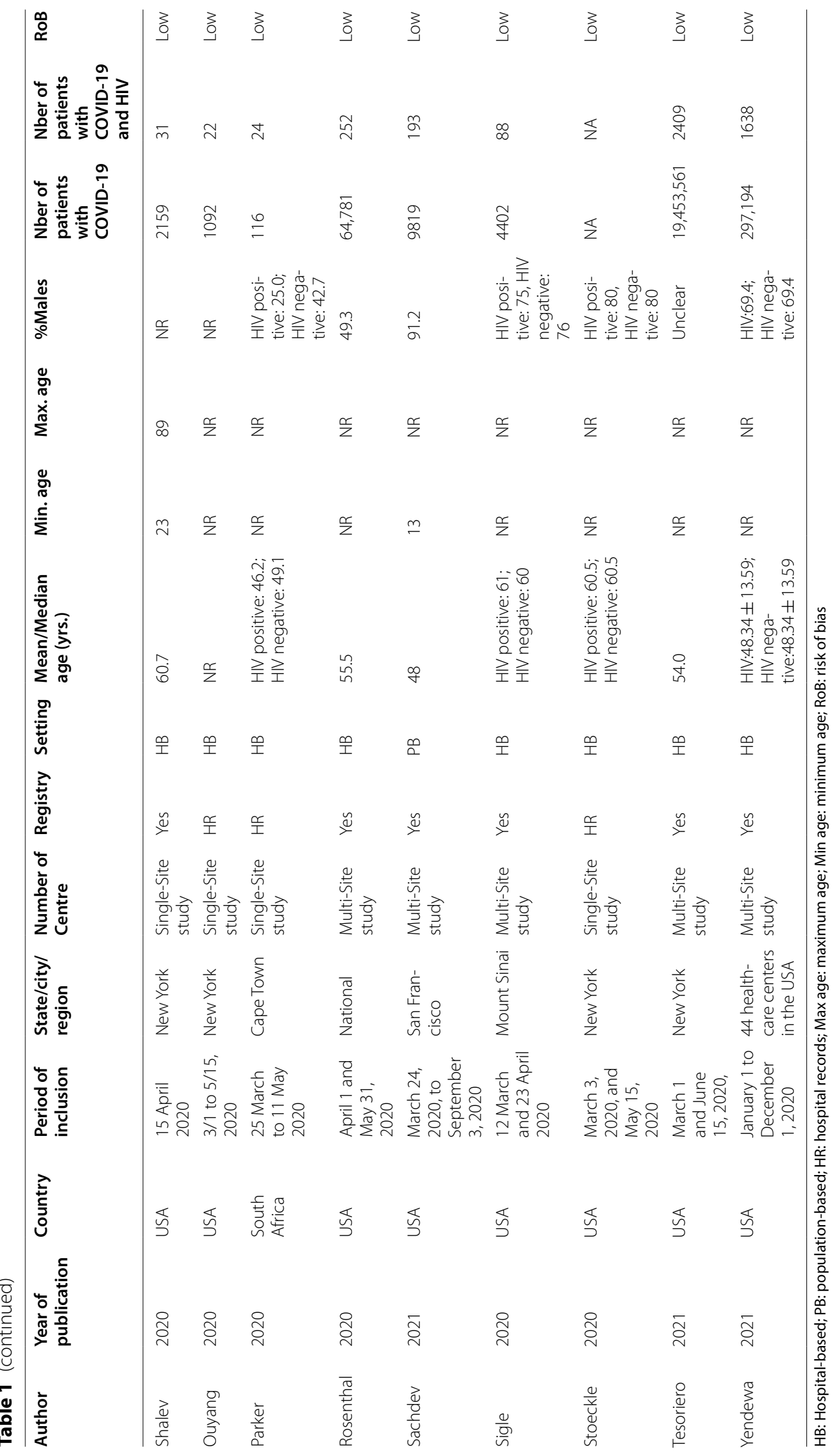




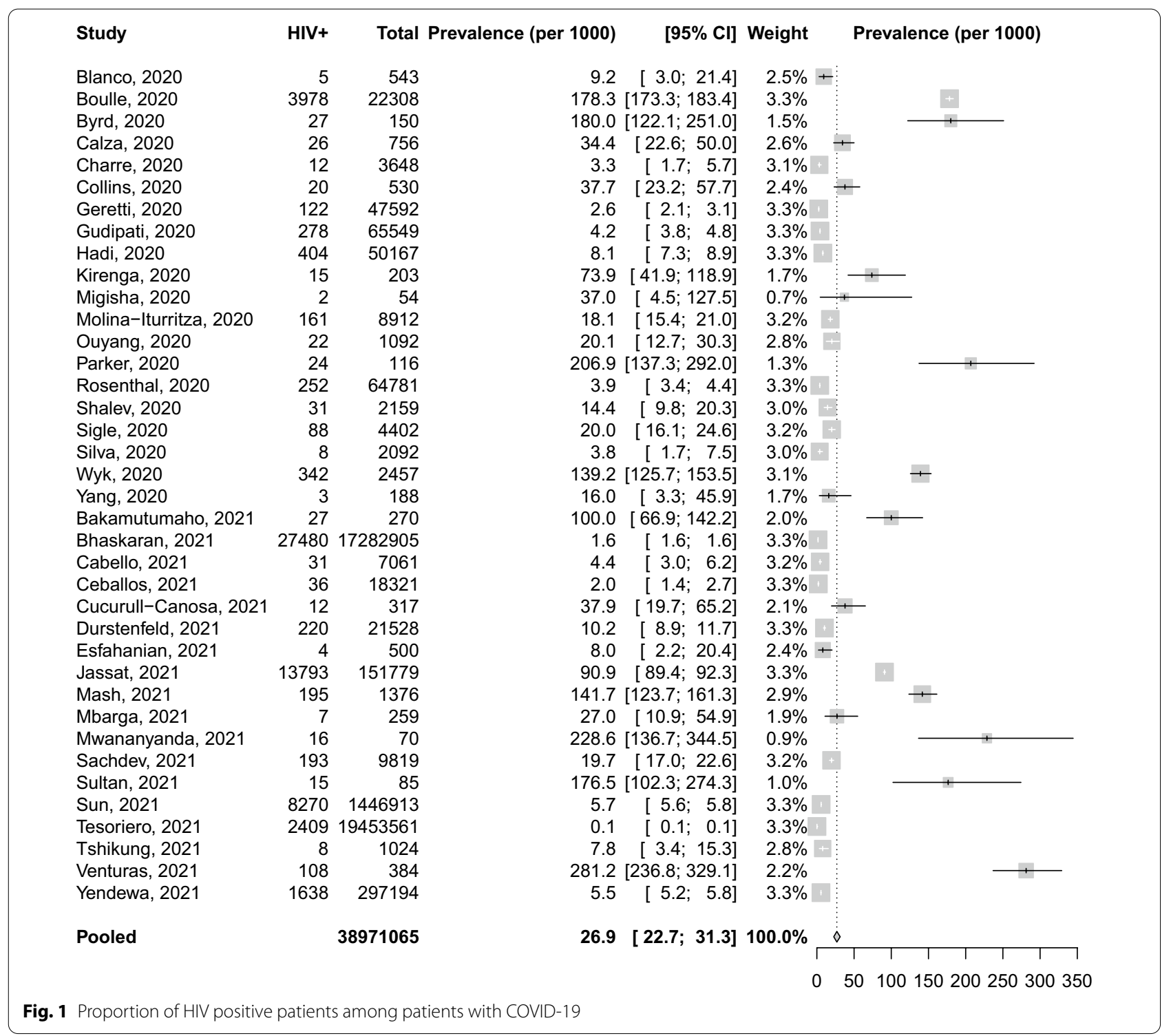

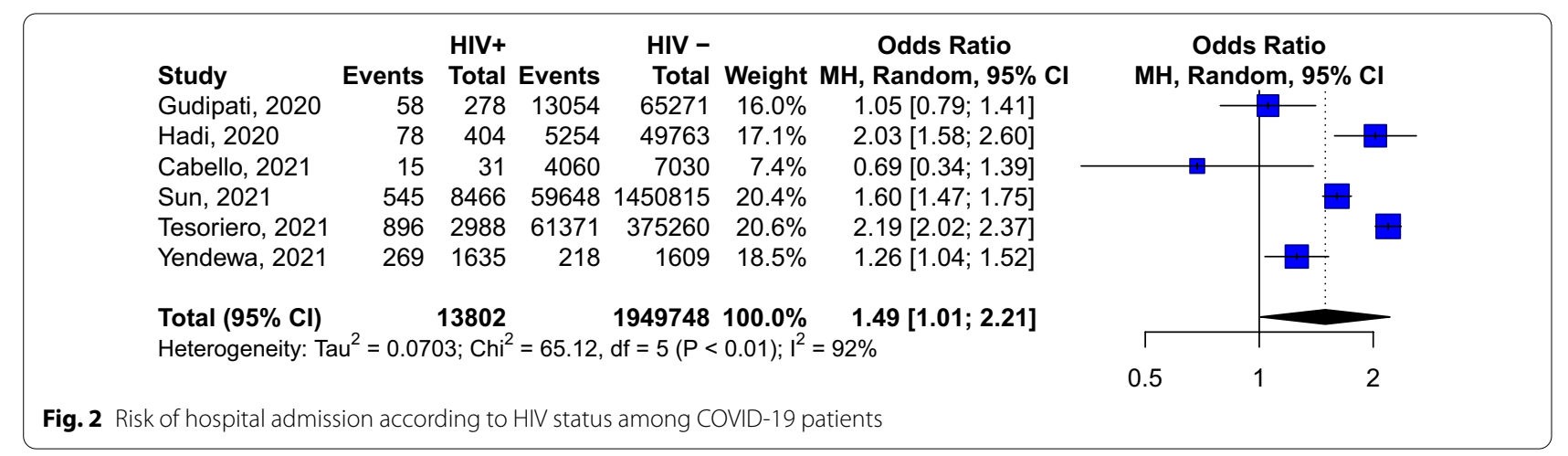




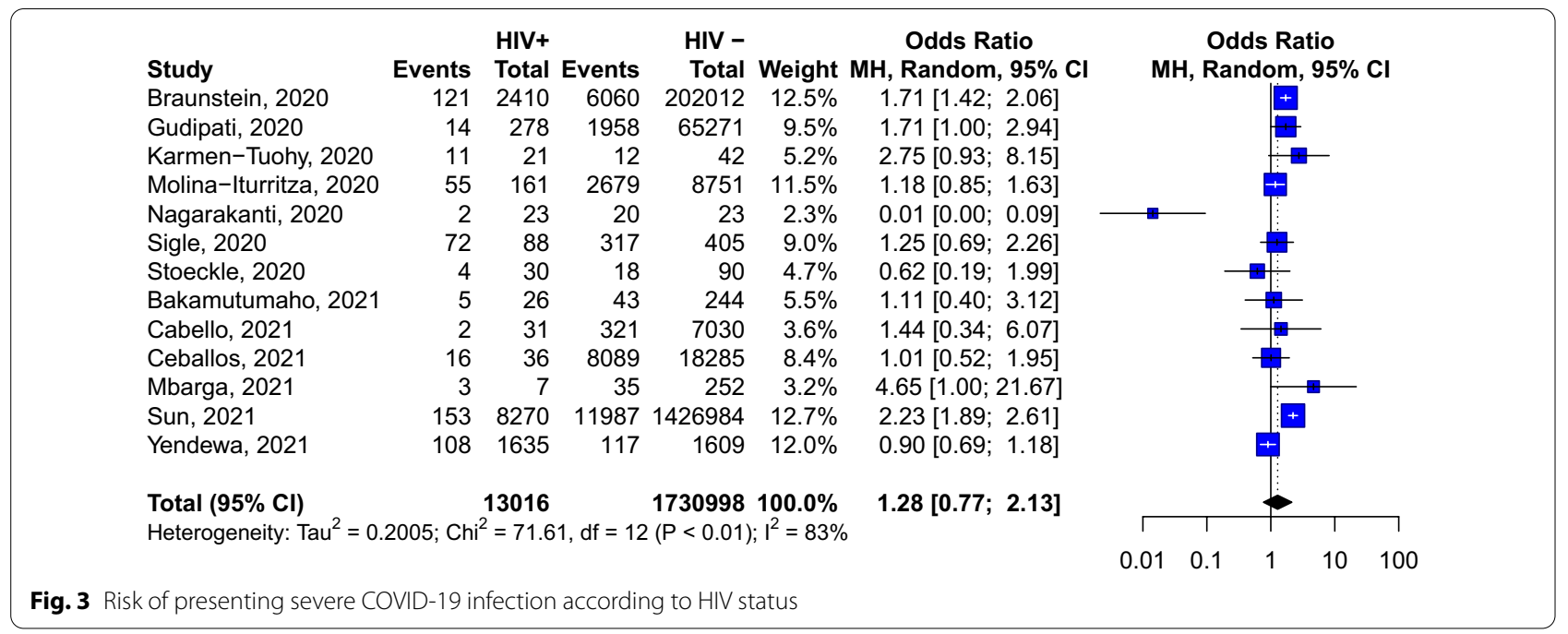

with COVID-19 in previous meta-analyses on the topic is probably because these meta-analyses pooled unadjusted estimators $[14,33]$.

Indeed, in our study, when pooling the unadjusted risk ratios, no difference in terms of mortality is observed. This contradictory result draws attention on the need to consider homogeneously adjusted estimators in the meta-analyses rather than raw estimators [11]. The possibility that the effect observed in the unadjusted analysis is attributable to sex cannot be excluded, as sex is known to influence the outcome of COVID-19 patients [34-40]. Our findings could have been different if the analyses had been stratified according to CD4 count or ARV protocol. Indeed, some ARVs such as tenofovir disoproxil fumarate/emtricitabine (TDF/FTC) are reported to be potentially effective against COVID-19 and could have a protective effect in patients on these drugs, thus modifying the natural history of the disease in patients treated with these medications [41-44]. In addition, CD4 count and lymphopenia, are known to be associated with disease severity and could have an impact on the evolution of COVID-19, as one of the main mechanisms underlying COVID-19-related morbidity and mortality is cytokine storm [45]. Deep immunodepression and low CD4 count could therefore increase the probability of having lymphopenia and a pejorative course of COVID-19 in HIV patients. Indeed in two recent studies presented in the conference on retrovirus and opportunistic infections (CROI), the mortality rate between HIV-positive and HIV-negatives patients with COVID-19 was not statistically different in treated and well- controlled patients [46, 47].

The relationship between age and increased comorbidities in HIV-positive patients compared to their negative counterparts is well established. The presence of inflammation in patients with HIV, even under effective ART, is thought to be the cause of renal, cardiovascular, and neurological diseases $[48,49]$. These comorbidities are associated with poor outcomes of COVID-19 [44, 49].

Our results point to a potential increased risk of admission for COVID-19 in HIV-infected individuals. This probably reflects the conservative approach used by physicians for this category of patients, given the inconsistent evidence regarding their outcome. Indeed, knowing the vulnerability of HIV patients to infections due to the pathophysiology of the disease [43], physicians may be inclined to admit HIV-positive individuals more easily than HIV-uninfected individuals, in order to better monitor them in hospital and anticipate the occurrence of any potential complications.

Our results also shows that co-infection with HIV does not increase the risk of presenting severe forms of COVID-19 as previously found by other authors [12]. Several hypotheses have been suggested to explain this phenomenon. The most plausible of which is the presence of immunodepression, which prevents patients from triggering and maintaining the cytokine storm responsible for the inflammatory manifestations of the disease, and which intensity is correlated with the severity of the disease. However, this claim would only be valid in HIV-immunocompromised patients with low CD4 counts and high viral load. A meta-analysis stratifying the outcomes according to $\mathrm{CD} 4$ count would therefore make it possible to distinguish whether severely immunocompromised patients are less likely to present severe COVID-19 compare with patients on ARVs with a CD4 count above 200 cells $/ \mathrm{mm}^{3}$. This especially because some studies have shown a worser 


\section{A-Meta-analysis of unadjusted Odds ratio (OR)}

\begin{tabular}{|c|c|c|c|c|c|c|c|}
\hline Study & Events & $\begin{array}{l}\text { HIV+ } \\
\text { Total }\end{array}$ & Events & $\begin{array}{l}\text { HIV - } \\
\text { Total }\end{array}$ & Weight & $\begin{array}{r}\text { Odds Ra } \\
\text { MH, Random }\end{array}$ & $95 \% \mathrm{Cl}$ \\
\hline Boulle, 2020 & 115 & 3978 & 510 & 18330 & $4.5 \%$ & $1.04[0.85$ & $1.28]$ \\
\hline Geretti, 2020 & 30 & 122 & 13969 & 47470 & $4.5 \%$ & $0.78[0.52 ;$ & 1.18] \\
\hline Gudipati, 2020 & 23 & 278 & 5942 & 65271 & $4.5 \%$ & $0.90[0.59$ & 1.38] \\
\hline Hadi, 2020 & 20 & 404 & 1585 & 49763 & $4.5 \%$ & $1.58[1.01 ;$ & 2.49] \\
\hline Molina-Iturritza, 2020 & 23 & 106 & 1235 & 8751 & $4.5 \%$ & $1.69[1.06 ;$ & 2.69] \\
\hline Nagarakanti, 2020 & 3 & 23 & 6 & 23 & $4.3 \%$ & $0.42[0.09$ & $1.96]$ \\
\hline Ouyang, 2020 & 4 & 22 & 213 & 1070 & $4.4 \%$ & $0.89[0.30 ;$ & $2.67]$ \\
\hline Parker & 6 & 24 & 22 & 89 & $4.4 \%$ & $1.02[0.36$ & 2.88] \\
\hline Rosenthal, 2020 & 37 & 252 & 7318 & 64529 & $4.5 \%$ & $1.35[0.95 ;$ & 1.91] \\
\hline Sigle, 2020 & 18 & 88 & 81 & 405 & $4.5 \%$ & $1.03[0.58$ & 1.82] \\
\hline Stoeckle, 2020 & 2 & 30 & 14 & 90 & $4.3 \%$ & $0.39[0.08$ & $1.82]$ \\
\hline Bhaskaran, 202 & 25 & 27480 & 14857 & 17255425 & $4.5 \%$ & $1.06[0.71 ;$ & $1.56]$ \\
\hline Cabello, 2021 & 1 & 31 & 903 & 7030 & $4.1 \%$ & $0.23[0.03$ & 1.66] \\
\hline Ceballos, 2021 & 5 & 36 & 4360 & 18285 & $4.4 \%$ & $0.52[0.20$ & 1.33] \\
\hline Díez, 2021 & 2 & 21 & 12 & 105 & $4.2 \%$ & $0.82[0.17 ;$ & 3.95] \\
\hline Id, 2021 & 36 & 220 & 3290 & 21308 & $4.5 \%$ & $1.07[0.75$ & 1.53] \\
\hline , 2021 & 4 & 4 & 151 & 496 & $2.2 \%$ & \multicolumn{2}{|c|}{$93.64[0.18 ; 49784.41]$} \\
\hline Jassat, 2021 & 3407 & 34104 & 30697 & 34104 & $4.5 \%$ & $0.01[0.01$ & $0.01]$ \\
\hline Lee, 2021 & 13 & 68 & 35 & 181 & $4.5 \%$ & $0.99[0.49 ;$ & $2.00]$ \\
\hline Sun, 2021 & 196 & 8270 & 23831 & 1426984 & $4.5 \%$ & $1.43[1.24 ;$ & 1.65] \\
\hline Tesoriero, 2021 & 207 & 2409 & 14522 & 375260 & $4.5 \%$ & $2.34[2.02 ;$ & $2.70]$ \\
\hline Venturas, 2021 & 16 & 108 & 54 & 276 & $4.5 \%$ & $0.71[0.39 ;$ & 1.31] \\
\hline Yendewa, 2021 & 46 & 1635 & 61 & 1609 & $4.5 \%$ & $0.73[0.50$ & $1.08]$ \\
\hline 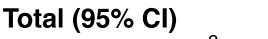 & & 79713 & & & & $0.81[0.47 ;$ & 1.41] \\
\hline
\end{tabular}

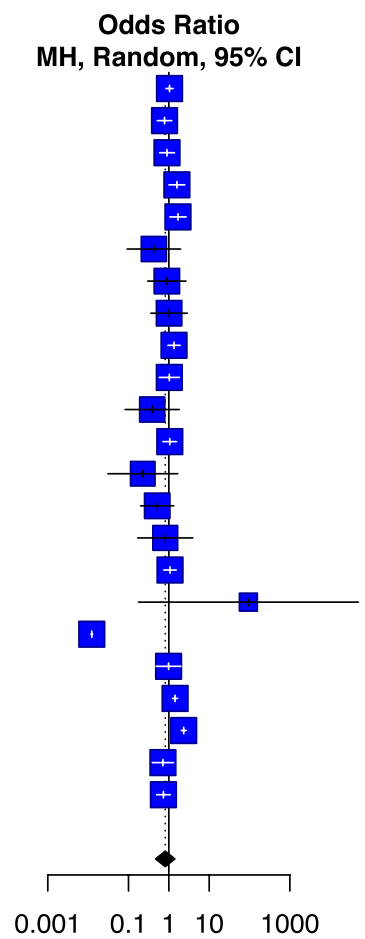

B-Meta-analysis of adjusted Hazard ratio

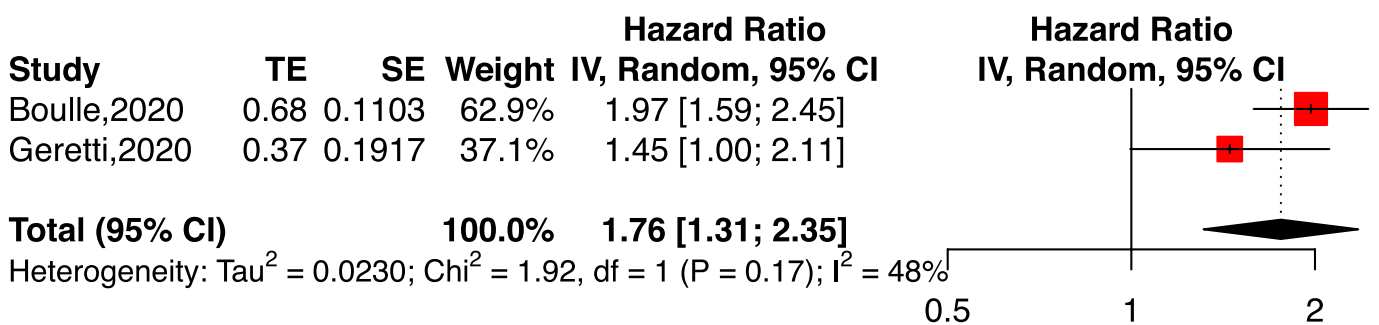

Fig. 4 Risk of death among COVID-19 patients according to HIV status. Meta-analysis of adjusted and unadjusted estimates

prognosis in patients with CD4 counts below $200 / \mathrm{mm}^{3}$ [48]. Unfortunately, few studies included in our metaanalysis stratified their results according to CD4 count, making it difficult to pooled studies according to CD4 count and to assess the veracity of this hypothesis using available evidence.

The current study highlights the need to consider HIV patients as a sub-population at high risk of hospital admission. They also call for more studies stratifying their analyses according to the different conditions (gender, age) and comorbidities known to influence the course of COVID-19, to clarify the contribution of HIV in disease progression.

Several reviews have attempted to synthesise outcome information for HIV patients with COVID-19 $[12-17,50]$. However, these studies have either included preprints and therefore unpublished articles in peerreviewed journals, or they have meta-analysed unadjusted estimators, ignoring the potential difference in the composition of the study populations and, more importantly, the presence of factors such as co-morbidities other than HIV that could influence outcomes in 
primary studies. The strength of our study was to give for the first time a meta-analysis of adjusted estimators and to included only articles published in peer review journals. Furthermore, the pooled sample size in our metaanalysis was high (38,971,065 patients with COVID-19). However, some limitations of the current study are the absence of the stratification of the analysis according to ART regimen, and the level of CD4. This was due to the lack of sufficient information to conduct these subgroup analyses. Secondly the number of studies included in the meta-analysis of adjusted point estimates was low.

\section{Conclusion}

Findings of the current review suggest that patients with HIV have an increased risk of hospital admission. Although crude analysis did not show an association between HIV infection and an increased risk of death or of developing severe disease in patients with COVID-19, adjusted data from two studies suggest that HIV infection increased the risk of mortality due to COVID-19. However, this later evidence was weak as it was derived from only two studies.

\section{Supplementary Information}

The online version contains supplementary material available at https://doi. org/10.1186/s12981-021-00427-y.

Additional file 1. Additional Figures and Tables.

\section{Acknowledgements}

None.

\section{Financial disclosures}

Dr. Danwang is supported by a scholarship from the Université catholique de Louvain. Dr. Noubiap is supported by a postgraduate scholarship from the University of Adelaide.

\section{Authors' contributions}

JC conceived the original idea of the study. CD and JJN selected the studies, extracted the relevant information, and synthetized the information. CD and JJN did the literature search. CD performed analyses and wrote the first draft of the paper with inputs from JC, AR and JJN. All authors critically revised successive drafts of the paper. All authors read and approved the final manuscript.

\section{Funding}

This study received no funding.

\section{Availability of data and materials}

All materials are available in the manuscript and additional file.

\section{Declarations}

Ethics approval and consent to participate

Not applicable.

\section{Consent for publication}

All authors approved the final version of the manuscript and agree for publication.

\section{Competing interests}

We declare no competing interests.

\section{Author details}

${ }^{1}$ Epidemiology and Biostatistics Unit, Institut de Recherche Expérimentale et Clinique, Université Catholique de Louvain, Brussels, Belgium. ${ }^{2}$ Centre for Heart Rhythm Disorders, University of Adelaide and Royal Adelaide Hospital, Adelaide, Australia. ${ }^{3}$ Department of Internal Medicine and Infectious Diseases, HIV/AIDS Reference Center, Cliniques Universitaires Saint-Luc, Avenue Hippocrate 10, 1200 Brussels, Belgium.

Received: 2 June 2021 Accepted: 20 December 2021

Published online: 14 January 2022

\section{References}

1. Nicola M, Alsafi Z, Sohrabi C, Kerwan A, Al-Jabir A, losifidis C, et al. The socio-economic implications of the coronavirus pandemic (COVID-19): a review. Int J Surg. 2020:78:185-93.

2. Sen P, Yamana TK, Kandula S, Galanti M, Shaman J. Burden and characteristics of COVID-19 in the United States during 2020. Nature. 2021;598(7880):338-41.

3. Chen S, Prettner K, Kuhn M, Bloom DE. The economic burden of COVID19 in the United States: Estimates and projections under an infectionbased herd immunity approach. J Econ Ageing. 2021;20:100328.

4. WHO Coronavirus (COVID-19) Dashboard. https://covid19.who.int. Accessed 3 Nov 2021.

5. Polack FP, Thomas SJ, Kitchin N, Absalon J, Gurtman A, Lockhart S, et al. Safety and efficacy of the BNT162b2 mRNA Covid-19 vaccine. N Engl J Med. 2020;383(27):2603-15.

6. Hall VJ, Foulkes S, Saei A, Andrews N, Oguti B, Charlett A, et al. COVID-19 vaccine coverage in health-care workers in England and effectiveness of BNT162b2 mRNA vaccine against infection (SIREN): a prospective, multicentre, cohort study. Lancet. 2021:397(10286):1725-35.

7. Lopez Bernal J, Andrews N, Gower C, Gallagher E, Simmons R, Thelwall S, et al. Effectiveness of Covid-19 vaccines against the B.1.617.2 (Delta) Variant. N Engl J Med. 2021;385(7):585-94.

8. Thompson MG, Stenehjem E, Grannis S, Ball SW, Naleway AL, Ong TC, et al. Effectiveness of Covid-19 vaccines in ambulatory and inpatient care settings. N Engl J Med. 2021;385(15):1355-71.

9. Osibogun A, Balogun M, Abayomi A, Idris J, Kuyinu Y, Odukoya O, et al. Outcomes of COVID-19 patients with comorbidities in southwest Nigeria. PLOS ONE. 2021;16(3):e0248281.

10. Sanyaolu A, Okorie C, Marinkovic A, Patidar R, Younis K, Desai P, et al. Comorbidity and its impact on patients with COVID-19. SN Compr Clin Med. 2020;25:1-8.

11. Cho SI, Yoon S, Lee H-J. Impact of comorbidity burden on mortality in patients with COVID-19 using the Korean health insurance database. Sci Rep. 2021;11(1):6375

12. Lee KW, Yap SF, Ngeow YF, Lye MS. COVID-19 in people living with HIV: a systematic review and meta-analysis. Int J Environ Res Public Health. 2021;18(7):3554.

13. Ssentongo P, Heilbrunn ES, Ssentongo AE, Advani S, Chinchilli VM, Nunez $J$ J, et al. Epidemiology and outcomes of COVID-19 in HIV-infected individuals: a systematic review and meta-analysis. Sci Rep. 2021;11:6282.

14. Liang M, Luo N, Chen M, Chen C, Singh S, Singh S, et al. Prevalence and mortality due to COVID-19 in HIV Co-infected population: a systematic review and meta-analysis. Infect Dis Ther. 2021;10(3):1267-85.

15. SeyedAlinaghi S, Karimi A, MohsseniPour M, Barzegary A, Mirghaderi SP, Fakhfouri A, et al. The clinical outcomes of COVID-19 in HIV-positive patients: a systematic review of current evidence. Immun Inflamm Dis. 2021;9(4):1160-85.

16. de Medeiros KS, da Silva LAS, de Macêdo LT, Sarmento AC, Costa APF, Eleutério JJ, et al. Potential impact of the COVID-19 in HIV-infected individuals: a systematic review impact of the COVID-19 in HIV-infected individuals. Rev Assoc Med Bras. 2021;67:127-56.

17. Mellor MM, Bast AC, Jones NR, Roberts NW, Ordóñez-Mena JM, Reith AJM et al. Risk of adverse coronavirus disease 2019 outcomes for people living with HIV. AIDS. 2021;35(4):F1-10. 
18. UNAIDS data 2020. https://www.unaids.org/en/resources/documents/ 2020/unaids-data. Accessed 16 May 2021.

19. Ambrosioni J, Blanco JL, Reyes-Urueña JM, Davies M-A, Sued O, Marcos MA, et al. Overview of SARS-CoV-2 infection in adults living with HIV. Lancet HIV. 2021;8(5):e294-305.

20. HIV/AIDS. WHO | Regional Office for Africa. https://www.afro.who.int/ health-topics/hivaids. Accessed 3 Nov 2021.

21. Dwyer-Lindgren L, Cork MA, Sligar A, Steuben KM, Wilson KF, Provost NR, et al. Mapping HIV prevalence in sub-Saharan Africa between 2000 and 2017. Nature. 2019;570(7760):189-93.

22. Richman DD. Normal physiology and HIV pathophysiology of human T-cell dynamics. J Clin Invest. 2000;105(5):565-6.

23. Kouanfack OSD, Kouanfack C, Billong SC, Cumber SN, Nkfusai CN, Bede F, et al. Epidemiology of opportunistic infections in HIV infected patients on treatment in accredited HIV treatment centers in Cameroon. Int J MCH AIDS. 2019;8(2):163-72.

24. Mellors JW, Muñoz A, Giorgi JV, Margolick JB, Tassoni CJ, Gupta P, et al. Plasma viral load and CD4+ lymphocytes as prognostic markers of HIV-1 infection. Ann Intern Med. 1997;126(12):946-54.

25. Emanuel EJ, Persad G, Upshur R, Thome B, Parker M, Glickman A, et al. Fair allocation of scarce medical resources in the time of Covid-19. N Engl J Med. 2020;382(21):2049-55.

26. Report of the WHO-China Joint Mission on Coronavirus Disease 2019 (COVID-19). https://www.who.int/publications-detail/report-of-the-whochina-joint-mission-on-coronavirus-disease-2019-(covid-19). Accessed 30 Apr 2020.

27. Joanna MJ, Institute B. Critical appraisal checklist for prevalence. Studies. 2017;2017:7.

28. critical-appraisal-tools - Critical Appraisal Tools | Joanna Briggs Institute. https://jbi.global/critical-appraisal-tools. Accessed 2 Nov 2021.

29. Higgins JPT, Thompson SG. Quantifying heterogeneity in a meta-analysis. Stat Med. 2002;21(11):1539-58.

30. Cochran WG. The combination of estimates from different experiments. Biometrics. 1954;10(1):101-29.

31. Biswas M, Rahaman S, Biswas TK, Haque Z, Ibrahim B. Association of sex, age, and comorbidities with mortality in COVID-19 patients: a systematic review and meta-analysis. INT. 2021;64(1):36-47.

32. Costenaro P, Minotti C, Barbieri E, Giaquinto C, Donà D. SARS-CoV-2 infection in people living with HIV: a systematic review. Rev Med Virol. 2021;31(1):1-12.

33. Choy K-T, Wong AY-L, Kaewpreedee P, Sia SF, Chen D, Hui KPY, et al. Remdesivir, lopinavir, emetine, and homoharringtonine inhibit SARS-CoV-2 replication in vitro. Antiviral Res. 2020;178:104786.

34. Del Amo J, Polo R, Moreno S, Díaz A, Martínez E, Arribas JR, et al. Incidence and severity of COVID-19 in HIV-positive persons receiving antiretroviral therapy: a cohort study. Ann Intern Med. 2020;173(7):536-41.

35. Danwang C, Endomba FT, Nkeck JR, Wouna DLA, Robert A, Noubiap JJ. A meta-analysis of potential biomarkers associated with severity of coronavirus disease 2019 (COVID-19). Biomark Res. 2020;8:37.

36. Characterizing Covid-19 presentation and clinical outcomes in HIV patients in the US. https://www.natap.org/2021/CROI/croi_109.htm. Accessed 16 May 2021.

37. COVID-19 in hospitalized HIV-positive and HIV-negative patients: a matched study [Internet]. CROI Conference. https://www.croiconference. org/abstract/covid-19-in-hospitalized-hiv-positive-and-hiv-negativepatients-a-matched-study/. Accessed 19 May 2021.

38. Shi Y, Yu X, Zhao H, Wang H, Zhao R, Sheng J. Host susceptibility to severe COVID-19 and establishment of a host risk score: findings of 487 cases outside Wuhan. Crit Care. 2020;24(1):108.

39. Jin J-M, Bai P, He W, Wu F, Liu X-F, Han D-M, et al. Gender differences in patients with COVID-19: focus on severity and mortality. Front Public Health. 2020;8:152.

40. Kopel J, Perisetti A, Roghani A, Aziz M, Gajendran M, Goyal H. Racial and gender-based differences in COVID-19. Front Public Health. 2020;8:418.

41. Falutz J, Brañas F, Erlandson KM. Frailty: the current challenge for aging people with HIV. Curr Opin HIV AIDS. 2021;16(3):133-40.

42. Ponatshego PL, Youssouf NF, Mosepele M. Current co-morbidities burden in patients living with HIV in low- and middle-income countries. Curr Opin HIV AIDS. 2021;16(3):163-7.
43. Justiz Vaillant AA, Naik R. HIV-1 Associated Opportunistic Infections. In: StatPearls. Treasure Island (FL): StatPearls Publishing; 2021. http://www. ncbi.nlm.nih.gov/books/NBK539787/. Accessed 3 Nov 2021.

44. Elfiky AA. Ribavirin, Remdesivir, Sofosbuvir, Galidesivir, and Tenofovir against SARS-CoV-2 RNA dependent RNA polymerase (RdRp): a molecular docking study. Life Sci. 2020;253:117592.

45. Melo AKG, Milby KM, Caparroz ALMA, Pinto ACPN, Santos RRP, Rocha AP, et al. Biomarkers of cytokine storm as red flags for severe and fatal COVID-19 cases: a living systematic review and meta-analysis. PLOS ONE. 2021;16(6):e0253894.

46. Chen LYC, Quach TTT. COVID-19 cytokine storm syndrome: a threshold concept. Lancet Microbe. 2021;2(2):e49-50.

47. Tang Y, Liu J, Zhang D, Xu Z, Ji J, Wen C. Cytokine storm in COVID-19: the current evidence and treatment strategies. Front Immunol. 2020;11:1708.

48. 5th Joint Conference of the British HIV Association (BHIVA) with the British Association for Sexual Health and HIV (BASHH). https://www.bhiva.org/ AnnualConference2021. Accessed 3 Nov 2021

49. Foresta C, Rocca MS, Di Nisio A. Gender susceptibility to COVID-19: a review of the putative role of sex hormones and X chromosome. J Endocrinol Invest. 2021;44(5):951-6.

50. Hariyanto TI, Rosalind J, Christian K, Kurniawan A. Human immunodeficiency virus and mortality from coronavirus disease 2019: a systematic review and meta-analysis. South Afr J HIV Med. 2021;22(1):1220.

\section{Publisher's Note}

Springer Nature remains neutral with regard to jurisdictional claims in published maps and institutional affiliations.

Ready to submit your research? Choose BMC and benefit from:

- fast, convenient online submission

- thorough peer review by experienced researchers in your field

- rapid publication on acceptance

- support for research data, including large and complex data types

- gold Open Access which fosters wider collaboration and increased citations

- maximum visibility for your research: over $100 \mathrm{M}$ website views per year

At BMC, research is always in progress.

Learn more biomedcentral.com/submissions 